\title{
Atuação docente em Educação Física escolar na Educação de Jovens e Adultos (EJA): ações de Promoção da Saúde
}

\author{
Julio Cesar Gomes da Costa $\left.{ }^{\mathrm{*}}{ }^{(}\right)$, Cláudia Teresa Vieira de Souza ${ }^{\mathrm{C}}$, Rosa Malena de Araújo Carvalho ${ }^{\mathrm{b}}$ ()
}

Palavras Chave:

Educação física escolar;

Formação continuada

de professores;

Promoção da saúde;

Educação de jovens e adultos.

\section{Keywords:}

School physical education;

Continuing teacher training;

Health promotion; Youth and adult education.

\section{RESUMO}

O objetivo deste estudo foi conhecer como os professores de Educação Física vem desenvolvendo suas aulas em torno da temática de Promoção da Saúde na Educação de Jovens e Adultos (EJA), uma modalidade da educação básica brasileira. A pesquisa, de caráter qualitativo, adotou como estratégia a entrevista individual com 10 professores através de curso de extensão, e utilizou como instrumento de análise de dados o Discurso do Sujeito Coletivo. Os resultados apontam que o discurso biologicista continua hegemônico nas concepções dos professores de Educação Física, possuindo um peso considerável nas reflexões de saúde e ser saudável, assim como, nas abordagens com esta temática na EJA.

\section{Palavras Chave:}

Educación física

escolar;

Formación contínua de professores;

Promoción de la salud; Educación de jóvenes y adultos.

\begin{abstract}
The aim of this study was to know how the Physical Education teachers, have been developing their classes around the theme of Health Promotion in the context of Youth and Adult Education, a form of Brazilian basic education. The research of qualitative approach, adopted as strategy ten individual interviews with teachers from the extension course, and used as a tool of analysis the technical discourse of the collective subject. The results presented point out that the biological discourse remains hegemonic in the conceptions of Health Promotion of Physical Education teachers, having a considerable weight in reflections on health and being healthy, as well as in the teaching approaches with this theme in this modality of education.
\end{abstract}

\section{RESUMEN}

El objetivo de este estudio fue conocer cómo los profesores de Educación Física vienen desarrollando sus clases en torno a la temática de Promoción de la Salud en la Educación de Jóvenes y Adultos (EJA), una modalidad de la educación básica brasileña. La investigación, de carácter cualitativo, adoptó como estrategia la entrevista individual con 10 profesores a través del curso de extensión ofrecido, y utilizó la técnica del Discurso del Sujeto Colectivo como instrumento de análisis de datos. Los resultados apuntan que el discurso biologicista continúa hegemónico en las concepciones de los profesores de Educación Física, teniendo un peso considerable en las reflexiones de salud y ser sano, así como en los abordajes con esta temática en la EJA.

\footnotetext{
a Fundação Oswaldo Cruz, Instituto Oswaldo Cruz, Rio de Janeiro, RJ, Brasil.

b Universidade Federal Fluminense, Departamento de Educação Física e Desportos, Niterói, RJ, Brasil.
}

\author{
*Autor correspondente: \\ Julio Cesar Gomes da Costa \\ E-mail: juliocosta92@gmail.com
}

Recebido em 5 de Agosto de 2019; Aceito em 8 de Outubro de 2019. 


\section{INTRODUÇÃO}

A Promoção da Saúde (PS) hoje pode ser entendida como um novo projeto para se pensar a saúde e a educação pública. Pela Organização Mundial da Saúde, o ideário vem, desde suas origens nos anos 70, tendo uma crescente influência nas políticas públicas, nas produções teórico-conceituais e nas práticas profissionais, inclusive, no que se refere à educação em saúde (Carvalho, 2004).

Devido às dissensões acerca do seu entendimento, as iniciativas de PS têm apresentado um caráter multifacetado tanto em sua definição como nas estratégias que são consideradas do seu âmbito (Czeresnia, 2016). Essa multiplicidade a respeito de seus conceitos e estratégias levou para o contexto escolar da Educação Física (EF) o surgimento de duas grandes correntes de pensamento acerca de como essa temática deve se materializar no trabalho docente, uma pelo desenvolvimento da aptidão física e outra pelo desenvolvimento da cultura corporal (Farinatti e Ferreira, 2006).

A primeira corrente, denominada por pesquisadores brasileiros de Saúde Renovada, pensa o tema da PS e suas relações com a EF a partir do desenvolvimento da aptidão física (resistência muscular, força, flexibilidade, composição corporal e resistência cardio-respiratória) pela atividade física (basicamente ginástica e esportes). A reflexão gira em torno do aumento dos perigos que as condições de vida urbana têm levado à saúde da sociedade moderna (transição epidemiológica), principalmente no que se refere à pandemia de doenças crônicas não transmissíveis, como o sedentarismo e a obesidade. Nesse processo de "adoecimento urbano", a corrente da Saúde Renovada defende que cabe à EF escolar direcionar o ensino para a criação de estilos de vida ativos e seus benefícios para a saúde, de modo a alcançar às alterações biológicas necessárias para garantir níveis de aptidão satisfatórios (Silva et al., 2013).

O ponto mais enfatizado pela Saúde Renovada é a autonomia criada pelo aluno sobre o planejamento do seu próprio programa de exercícios físicos. Assim, para que o aluno conheça os benefícios, a maneira correta de se exercitar, os diversos tipos de exercícios e os diferentes componentes da aptidão física, essa corrente entende que é preciso articular as atividades práticas com os conteúdos básicos das ciências naturais, como: fisiologia, biomecânica, nutrição e anatomia (Devide et al., 2005).

Já a segunda corrente, baseada numa visão ampliada de saúde, considera a influência dos aspectos multifatoriais (social, econômico, político, ambiental e cultural) para pensar as questões de PS e, que a abordagem da EF, pela cultura corporal, deve investir no desenvolvimento das práticas corporais (brincadeiras, jogos, danças, ginásticas, dentre outras) pelo pensamento crítico, de modo a articular seus conteúdos de ensino com reflexões que auxiliem o aluno na análise crítica dos problemas contemporâneos de saúde. Assim, essa corrente entende que a EF escolar pode contribuir na produção de modos de vida saudáveis e em atitudes promotoras de saúde através da ampliação do olhar sobre a saúde e ser saudável para além da esfera biológica, pela articulação do tema às questões políticosociais e pela valorização das culturas locais a partir dos conteúdos da EF (Brasil, 2014; Nogueira, 2014).

Ao aproximar essas perspectivas da Educação de Jovens e Adultos (EJA), uma modalidade da educação básica brasileira, o que se problematiza são as orientações pedagógicas dessas correntes com as características e funções específicas - reparadora, equalizadora e permanente/qualificadora - que norteiam os fundamentos desta modalidade (Brasil, 2000).

A função reparadora da EJA refere-se ao reconhecimento das desigualdades sociais que a camada popular da sociedade brasileira foi submetida historicamente pelo Estado, ao tempo em que se ignorou de forma explícita a participação desses trabalhadores no desenvolvimento do país. Portanto, diz respeito à correção desse pé de desigualdade ao acesso à educação que a organização social levou a classe trabalhadora a viver historicamente.

A função equalizadora da EJA, diz respeito à necessidade de se formalizar um suporte específico à escolarização dos jovens e adultos. Os desfavorecidos frente ao acesso e permanência na escola devem receber proporcionalmente maiores oportunidades que os outros. Assim, a função equalizadora representa a cobertura a trabalhadores e a tantos outros segmentos sociais como donas de casa, migrantes, aposentados e encarcerados, de modo que permita a este público sempre voltar ao ponto de onde parou, sem qualquer prejuízo.

A função qualificadora vista como a função mais importante da EJA, expressa o próprio sentido desta modalidade. A função qualificadora tem como base o caráter incompleto do ser humano cujo potencial sempre esteve o poder de se qualificar, e descobrir novos campos de atuação como realização de si. Assim, uma oportunidade educacional pode ser a abertura para a emergência de um artista, de um intelectual ou da descoberta de uma vocação pessoal.

Portanto, alimentar o debate em torno de qual modelo de PS dialoga com os objetivos educacionais da Educação de Jovens e Adultos, significa pensar em um enfoque que seja motivador de transformações e de participações culturais e políticas mobilizadas a criar outro tipo de vida social, mais justa, mais humana, igualitária e solidária (Brandão, 2008). 
Essa pesquisa parte do entendimento de que, ao se eleger a perspectiva da aptidão física, com valorização estritamente epidemiológica e biológica da atividade física, resgata-se uma concepção de EF que muitos de nós tentamos superar e ir além, de caráter instrumental, não histórica, "neutra" política e ideologicamente, sob as bases de uma falsa consciência de que o exercício, por si só, é responsável pelo status de saúde individual. Imputa-se aos alunos a necessidade da prática de exercício físico para a conquista da saúde, mas não se considera a ausência do setor público nas políticas saudáveis, e as condições de vida desse grande grupo social da EJA. O que contribui, em última análise, para a culpabilização das vítimas e desresponsabilização do Estado (Mezzaroba, 2012).

Portanto, repensar a saúde não como ausência de doenças, mas como processo dinâmico de um fenômeno que materializa intenções, tensões e ações sócio-políticas, em um amplo espectro de possibilidades em constante movimento, significa perceber que ensinar o que é saudável, dependendo da abordagem adotada, pode servir tanto a projetos de manutenção do status quo quanto de transformação social (Ferreira, 2008). Diante disto, esta pesquisa considera que somente com o reconhecimento de um conjunto de aspectos capazes de ampliar a discussão sobre o conceito multifatorial de PS articulados à tematização crítica-reflexiva da cultura corporal, é que se torna possível contribuir significativamente na construção de identidades comprometidas com a reflexividade crítica e em atitudes promotoras de saúde.

Adotando um posicionamento a favor da perspectiva ampliada de PS, o artigo investiga como os professores de EF, atuantes na EJA, vem desenvolvendo a temática em torno desta modalidade.

\section{PROCEDIMENTOS METODOLÓGICOS}

Pela abordagem qualitativa, o estudo foi realizado em curso de extensão oferecido pelo Instituto de EF da Universidade Federal Fluminense, localizado no Estado do Rio de Janeiro. A escolha do referido curso deu-se por verificarmos características específicas que o destacam em relação a outros cursos de formação continuada, como: a preocupação em focar na EJA; discutir a inserção da EF nessa modalidade; além de ser um curso com uma trajetória de quase uma década de existência. Portanto, justifica-se por ser um curso comprometido em dar visibilidade às questões da EF no contexto da EJA, que em especial não recebem a devida atenção da área. Silva (2010) aponta que a abordagem qualitativa é aquela que trabalha com valores, crenças, representações, hábitos, atitudes e opiniões. Ela aprofunda a complexidade dos fenômenos, fatos e processos; passa pelo observável e vai além dele ao estabelecer inferências e atribuir significados.
O grupo de informantes da pesquisa foi constituído por 10 professores licenciados em EF, inscritos no curso de extensão, que atuam na EJA. Como o curso tinha vagas estendidas a outros profissionais da Educação Básica das redes públicas do Rio de Janeiro, houve a necessidade de inserir critérios de inclusão e de exclusão para a realização deste estudo. Os critérios de inclusão adotados, foram: I) ser licenciado em EF; II) ser participante do curso de extensão; III) aceitar participar da pesquisa e assinar o Termo de Consentimento Livre e Esclarecido (TCLE). Já os critérios de exclusão, foram: professores licenciados em EF que não atuavam na EJA e/ou não tivessem interesse em participar da pesquisa. Trata-se de uma amostragem por conveniência, ou seja, não-aleatória, não probabilística, onde os elementos que dela fazem parte foram selecionados por um julgamento de valor e não por questões de aleatoriedade estatística (Pereira, 2008).

$\mathrm{Na}$ entrevista, perguntas semiestruturadas, permitindo explanação livre dos sujeitos em relação aos tópicos, com as respostas não condicionadas a uma padronização de alternativas (Manzini, 2004). As falas dos entrevistados foram gravadas e transcritas na íntegra, para tabulação dos dados de cada pergunta do roteiro, o qual contemplou questões relativas ao nível e ao ano de formação: graduação, pós-graduação (e áreas de titulação); tempo de atuação na EJA; percepção sobre o conceito de PS; possibilidades pedagógicas com esta temática nas aulas de EF na EJA; principais dificuldades e desafios para atuar com a PS na EJA; experiências (disciplinas, especializações, cursos, estágios, etc.) que tiveram durante a formação inicial ou continuada, que os capacitaram sobre PS. De acordo com Gil (2007), é conveniente fazer a mesma pergunta de formas diferentes a fim de ter uma visão mais abrangente do assunto.

Para a análise de dados, foi utilizada a técnica do Discurso do Sujeito Coletivo (DSC), organizando e tabulando os dados obtidos, trazendo os discursos individuais, extraindo as expressões-chave e ideias centrais para, ao final, trazer o pensamento síntese de uma coletividade.

A técnica do DSC é uma proposta de organização e tabulação de dados qualitativos de natureza verbal, obtido através dos depoimentos de cada participante. Essa técnica confere naturalidade, espontaneidade e vivacidade ao pensamento coletivo, o que contrasta fortemente com as metodologias clássicas de apresentação de resultados qualitativos (Lefèvre e Lefèvre, 2003).

Esta pesquisa foi encaminhada e aprovada pelo Comitê de Ética em Pesquisa, sob o número de CAAE: 68191217.6.0000.5248 atendendo a Resolução 466/13 sobre pesquisa envolvendo seres humanos.

\section{RESULTADOS E DISCUSSÃO}

No período em que ocorreu a coleta de dados (2017), 10 professores atenderam aos critérios de inclusão da 
pesquisa. Todos eles foram convidados e, aceitaram participar da pesquisa após assinatura do TCLE.

Sobre os entrevistados, $60 \%$ foram do sexo feminino. No que se refere ao nível de formação, 70\% dos professores são pós-graduados. Quanto às áreas de especialidade, $71,4 \%$ dos professores são especialistas na área escolar, e 28,6\% fizeram especialização na área da saúde. Em relação ao tempo em que atuam na EJA, todos os entrevistados relataram ter experiência que variou de 11 meses a 09 anos.

A partir das falas foi possível verificar que tanto os professores com maior tempo de trabalho na EJA, quanto os com menos tempo, apresentaram motivação e mobilização para buscar qualificação em seu trabalho pedagógico. Já no que se refere ao ano e ao nível de formação e as suas respectivas áreas de titulação, não foi identificado influência dessas categorias nas percepções e estratégias dos professores em relação à PS na EJA.

Para alcançarmos os resultados das falas do coletivo, recorremos à organização e tabulação dos dados qualitativos de natureza verbal. A partir dos quatro blocos com seus respectivos temas do roteiro de entrevista, organizamos um quadro esquemático com as figuras metodológicas: Ideias Centrais (IC) e Expressões-Chave (ECH) para descrever o Discurso do Sujeito Coletivo (DSC).

Em suma, a técnica do Discurso do Sujeito Coletivo é uma proposta de organização e tabulação de dados qualitativos de natureza verbal, buscando analisar o material verbal extraído de cada depoimento obtido durante a pesquisa. Por ter como matéria-prima os depoimentos dos participantes do estudo, os resultados da pesquisa qualitativa são apresentados sob a forma de um ou vários discursos-síntese, escritos na primeira pessoa do singular, visando expressar o pensamento de uma coletividade, como se esta coletividade fosse o emissor de um discurso único (Lefèvre e Lefèvre, 2003).

A partir da construção do DSC, criamos categorias, analisadas e apresentadas a seguir. Optamos em apresentar o DSC das categorias mais frequentes:

\section{Quadro 1. Percepção sobre Promoção da Saúde}

DSC: Eu acho que a Promoção da Saúde está relacionada à qualidade de vida, promover saúde é você ter um estilo de vida saudável, ter o hábito de uma boa alimentação, boas horas de sono, fazer atividade física regularmente, ter momentos de lazer, todas essas coisas para alcançar um bem-estar.

Fonte: Elaborado pelo autor.

Conforme o discurso acima, a categoria mais frequente foi "Ter um estilo de vida saudável" (80,0\%). A maioria dos professores relacionou o conceito de PS à qualidade de vida, ainda que este conceito também não esteja explicitamente definido, as características apontadas para ilustrar as percepções acerca de sua definição foram: prática regular de atividade física, alimentação saudável, boas horas de sono e momentos de lazer. A identificação destas características revela como a ideia de PS está fortemente atrelada a questões comportamentais, focalizando os aspectos da PS à esfera individual, principalmente, pelos estilos de vida. Assim, o entendimento sobre a PS é definido pela busca da conservação ou expansão da vitalidade, decorrentes de atividades e hábitos cotidianos que são afetados pelas escolhas a partir do que é biologicamente saudável (Carvalho, 2005).

Essa percepção sobre a PS, isolado das influências econômicas, políticas e culturais, reproduz uma concepção marcante construída pelo Paradigma Clássico ou Comportamental da PS que predominou os primeiros cenários deste ideário, a partir da década de 1970, principalmente com os relatórios Lalonde e Health People 1979, cuja ênfase está nos estilos de vida como resposta para diminuir os fatores de risco relacionados à saúde (Ferreira, 2008).

No Paradigma Clássico de PS, mesmo vinculando a interferência das questões ligadas a saúde à diversos fatores, as soluções para os problemas de saúde recaem nas escolhas individuais, sendo o indivíduo considerado como o único capaz de poder melhorar a sua própria saúde, através de hábitos saudáveis. Desta forma, confere a excessiva responsabilização do indivíduo por sua saúde e, não considera a influência dos aspectos sociais, econômicos, políticos, ambientais e culturais no acesso e nas escolhas daquilo que é considerado saudável.

A PS em sua concepção contemporânea é entendida como instrumento fundamental de luta pela melhoria da qualidade de vida, mas que considera um conjunto de recursos sociais e pessoais para atuar sobre os aspectos condicionantes da saúde. Isto significa que este ideário passa a reconhecer a importância de um projeto de sociedade abrangente e transformador que se expressa por diversas abordagens complementares e por ações coordenadas que apontem para a equidade em saúde, distribuição mais equitativa de renda, políticas sociais e a participação da sociedade (Rodrigues de Sá et al., 2016).

Buss (2016) explica que a PS deve ser entendida como um modo de pensar e de operar que articula as condições de vida e saúde, tomando como objeto de análise os problemas e as necessidades de saúde que atingem diretamente o dia a dia da população.

Isto quer dizer que a PS é uma ferramenta de transformação das condições de vida e de saúde dos sujeitos e coletividades respaldadas por uma visão integrada dos complexos problemas sociais da atualidade 
e através de múltiplas estratégias que envolvem atores sociais, instituições, saberes, práticas, englobando desta forma todos os componentes ligados à saúde: econômico, político, biológico, cultural (Carvalho, 2005).

Portanto, a compreensão da PS numa perspectiva restrita acaba sendo o primeiro obstáculo para uma abordagem crítica capaz de se conectar com a realidade dos alunos, uma vez que, ao conceder uma atenção exagerada aos aspectos físicos e comportamentais reforça-se a construção de um olhar biologicista de um fenômeno mais amplo e corre-se o risco de culpabilizar os sujeitos que na verdade são vítimas, na medida em que, não se reconhece os condicionantes que impedem, por vezes, a adoção de estilo de vida ativo.

Quadro 2. Promoção da Saúde na prática de ensino na EJA

DSC: Acredito que podemos contribuir trazendo informações para os alunos através de palestras ou projetos em parceria de outros profissionais da saúde para tratar de temas importantes, como: obesidade, hipertensão, diabetes; apresentar dados e estatísticas aos alunos, montar feiras de saúde na escola para verificar a pressão, IMC; trabalhar a importância da alimentação saudável, mostrar os benefícios de se fazer atividade física regularmente, em sua casa ou em seu trabalho, pois são práticas simples e possíveis de se fazer; então acredito que podemos contribuir por ai, em coisas assim.

Fonte: Elaborado pelo autor.

Neste DSC, 70\% dos entrevistados apontaram para a categoria "Ênfase nos estilos de vida e fatores de risco" como possibilidade do professor de EF trabalhar com a PS em sua prática de ensino na EJA.

A identificação desta categoria ilustra como as estratégias de PS estão pautadas em questões estritamente biológicas e comportamentais, remetendo as possibilidades pedagógicas aos fatores de riscos provenientes dos estilos de vida que afetam a saúde.

$O$ indício principal desta influência está na adesão ao discurso de que os alunos ao estarem informados sobre como realizar atividades saudáveis com segurança e eficiência poderão satisfazer suas próprias necessidades e interesses de saúde, realizando atividade física tanto em sua casa ou em seu trabalho, por se tratar de "práticas simples" e "possíveis" de se fazer. Ou seja, neste discurso o indivíduo desinformado é visto como o problema e, o acesso à informação para a mudança do seu estilo de vida é apontado como solução (Nogueira, 2014).

Contudo, no discurso apresentado observamos que não foram considerados aspectos relacionados à influência das condições de vida no acesso às práticas saudáveis, principalmente, quando pensamos nos alunos da EJA que são, em sua grande maioria, trabalhadores com menos oportunidades. Logo, a probabilidade desses alunos realizarem alguma prática corporal regularmente é menor do que a de alunos das classes média e alta, que vivem outra realidade.

Outro ponto é a defesa do acesso a conhecimentos da área biomédica. No DSC, a abordagem interdisciplinar é sugerida através de palestras com outros "profissionais de saúde" para tratar de temas como obesidade, hipertensão, diabetes; apresentar dados e estatísticas etc., mostrando a dificuldade em ir além dos conhecimentos da esfera biológica e, ao mesmo tempo, o desconhecimento de uma abordagem interdisciplinar da PS para formar uma integração com as dimensões culturais do aluno.

No que se refere aos conteúdos da EF, o DSC faz referência apenas ao caráter laboral, biológico e funcional da atividade física, no qual é reforçado um modelo de ação pedagógica tradicional, prescritiva e individualizada típico da corrente da Saúde Renovada, em detrimento de uma prática pedagógica que desenvolva a PS na perspectiva da cultura corporal (através de brincadeiras, jogos, dança, ginásticas, entre outras) pelo seu caráter mais lúdico, de modo que a produção de bem-estar seja estabelecida também pela criação de relacionamentos positivos, respeitoso e dialógico (Nogueira, 2014).

Quadro 3. Dificuldades e desafios da Promoção da Saúde na EJA.

DSC: Acho que o maior desafio é fazer com que os alunos consigam realizar alguma atividade física fora da escola. Pois, na escola eu até consigo convencer alguns alunos a fazerem alguma atividade. Mas, fora da escola, a maioria desanima e não faz mais nada. Então, o principal desafio é conseguir fazer com que eles pratiquem alguma coisa lá fora.

Fonte: Elaborado pelo autor.

Verificamos neste discurso que $54,54 \%$ dos entrevistados informaram a categoria "Levar os alunos a adotarem um estilo de vida ativo" como o principal desafio para atuar com a PS na EJA. De fato, promover estilos ativos de vida têm se tornado um grande desafio de muitos professores de EF, profissionais da saúde e instituições que atuam no campo da PS.

Apesar da existência de várias campanhas incentivando as pessoas a adotarem a prática regular de atividade física, e programas oferecendo ginástica gratuita em espaços públicos, o que se tem são resultados muito abaixo do esperado (Coelho e Verdi, 2015). Isto acontece porque a mudança de um estilo de vida não depende apenas das escolhas e desejos individuais, uma vez que, essas escolhas estão fortemente entrelaçadas ao contexto social (Czeresnia, 2016). Não considerar esta influência, corre-se o risco de responsabilizar os sujeitos que na verdade são vítimas. 
Quando levamos este debate para o contexto dos alunos da EJA, é possível perceber que grande parte desses alunos tem de lidar com uma rotina diária de trabalho extremamente exaustiva, o que faz com que sintam-se extremamente indispostos para se engajarem em alguma prática corporal de cunho mais fitness. Isto quer dizer que, mesmo quando os conhecimentos e as motivações existem, nem sempre serão o suficiente para induzir hábitos desejáveis, visto que o comportamento e as escolhas destes sujeitos estão fortemente integrados às suas vidas cotidianas.

Por isso, é fundamental que os professores estejam conscientes das influências de aspectos sociais na relação dos alunos com as práticas corporais, uma vez que, as desigualdades sociais representam um importante aspecto associado às condições de saúde da população.

Neste discurso, a categoria mais citada pelos entrevistados foi "Disciplinas da graduação" (45, 4\%), seguida por "Referenciais teóricos de base biomédica" (27, 24\%), como as principais experiências que tiveram na formação profissional para atuar com a PS.
Quadro 4. Formação profissional e Promoção da Saúde.

DSC: $A$ base principal eu tive na faculdade, tive algumas disciplinas que me ajudaram muito, depois fui buscando o conhecimento por minha conta, lendo livros e artigos de saúde e bem-estar, nutrição, atividade física, essas coisas. Mas, sobre alguma experiência acadêmica que tivesse discutido a Promoção da Saúde, numa perspectiva mais histórica, contextualizando sobre a sua origem, isso eu não tive não.

Fonte: Elaborado pelo autor.

Esta categoria permite observar que os professores se pautam nos domínios tradicionais da EF para avaliar sua qualificação sobre PS, cuja premissa está relacionada aos aspectos das respostas e adaptações fisiológicas decorrentes da atividade física.

Essa compreensão restrita de PS ilustra como as abordagens com este tema estão sendo ancoradas por um modelo prescritivo, individualizado e biológico de $\mathrm{EF}$, o que acaba limitando a compreensão dos alunos acerca dos demais conhecimentos relacionados aos elementos da cultura corporal para PS, como mostra a figura abaixo:

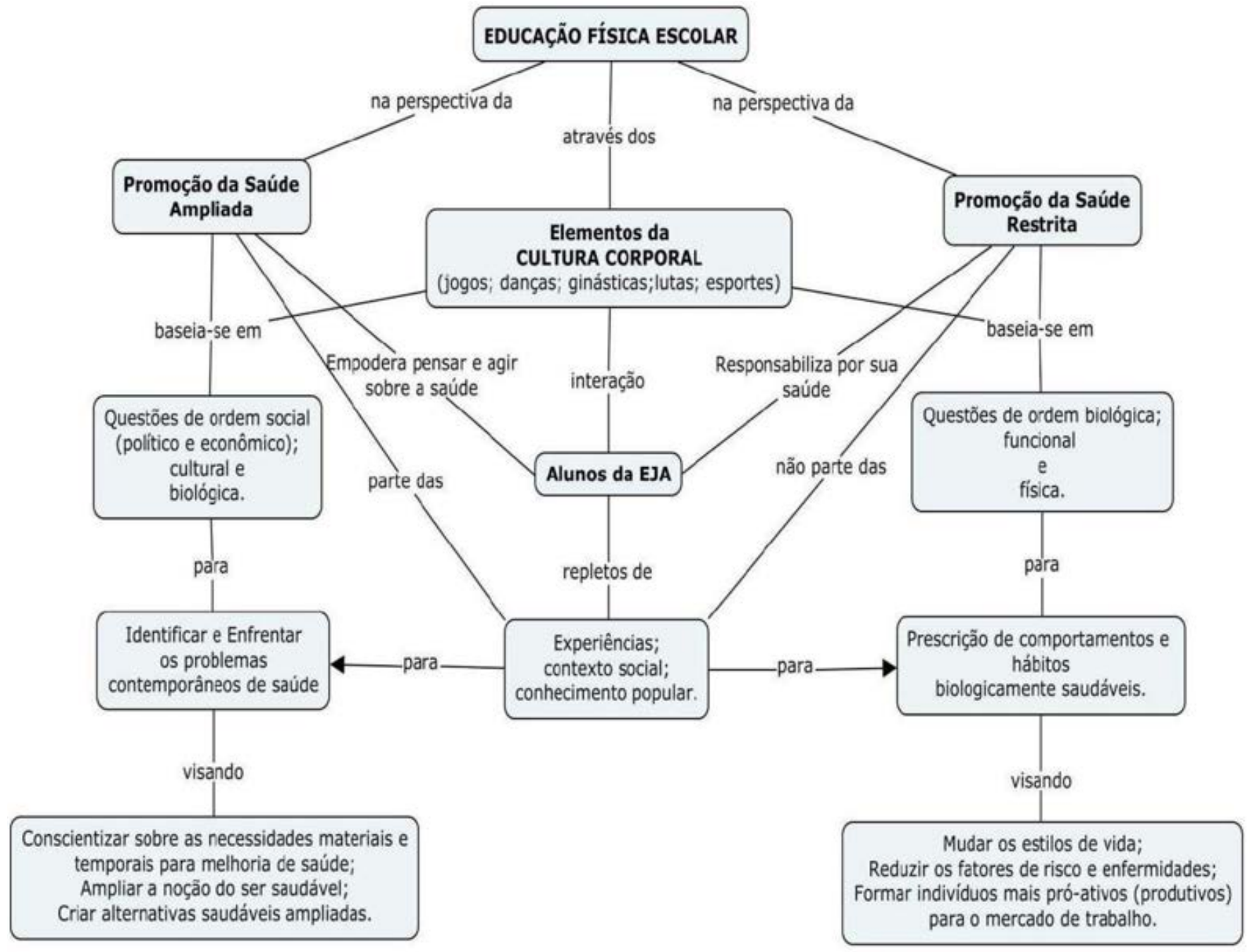

Figura 1. Características das abordagens de ensino da EF com a PS na perspectiva ampliada e na perspectiva restrita. Fonte: Elaborado pelo autor. 
Como pode ser visto acima, atuar na PS numa perspectiva ampliada significa criar a partir dos contextos, conhecimentos e as experiências dos alunos novas possibilidades de discussão desta temática, valorizando as experiências do universo vivencial do aluno para, em seguida, aprofundá-las e ampliá-las mediante o diálogo com outras manifestações corporais, destacando o prazer, ludicidade e alcance cultural que caracteriza este conteúdo, sem desconsiderar as contribuições que as ciências biológicas também tem a oferecer.

De maneira diferente na perspectiva restrita, os professores quando privilegiam os aspectos físicosmotores e/ou de aptidão física, acabam por reforçar uma ideia positivista do tema e dos conteúdos que não condizem com a direção que a EF contemporânea e a escola pública, de modo geral, tem tomado.

Abordar esta questão é relevante, pois o papel da EF com a PS no contexto escolar está mais relacionado à contribuição junto às demais disciplinas ao aprimoramento do educando como ser humano, em sua formação ética, no desenvolvimento de sua autonomia intelectual e de seu pensamento crítico a partir da reflexão sobre as questões que envolvem a temática, do que o desenvolvimento físico-motor, tático esportivo ou de aptidão física, como se propõem outros espaços de atuação do professor de EF.

\section{CONSIDERAÇÕES FINAIS}

Por meio dos DSCs foi possível conhecer como os professores de EF, atuantes na EJA, vêm desenvolvendo suas aulas em torno da temática de PS nessa modalidade da educação. A maioria dos professores entrevistados apresentou uma ideia restrita deste conceito, principalmente pautada numa perspectiva individualizante e biológica. Com isso, o discurso coletivo acabou expressando uma perspectiva que não contribui para um entendimento ampliado dos alunos no que se refere às questões da PS.

Embora avanços mais sistemáticos estejam sendo alcançados em termos conceituais, a produção de conhecimento no que se refere à saúde ainda encontrase pautada no olhar positivista. Isto se deve a própria trajetória curricular da EF que, apesar de diferentes áreas de influência, sempre esteve relacionada à ideia de que atividade física gera saúde.

Outro aspecto a ser observado no DSC é o reconhecimento dos professores da falta de uma formação específica para explorar e valorizar o tema da PS pelo seu caráter histórico e contextual. O que indica que o uso do termo vem sendo trabalhado pelos professores sem um estudo sistemático dos referenciais teóricos que discutem este ideário. Com isso, ideias pré-concebidas no imaginário da sociedade acabam sendo reforçadas pelos professores, como a de que o papel da EF no contexto escolar deve se pautar em dar instruções de como realizar exercícios físicos.

Esse contexto só será superado com atuações que possam ir além destas questões, quando o professor de EF for capaz de trabalhar com a PS por uma abordagem integral, cujas reflexões levem os alunos a perceber a saúde como uma questão que perpassa o problema médico, como é usual considera-la, para um trabalho de desenvolvimento humano, que promova uma sociedade dotada de conhecimento, raciocínio, crítica, responsabilidade, sensibilidade para as questões da vida e da sociedade.

Os estudos na área da EF escolar têm modificado significativamente, e isso se deve em grande parte à contribuição da Filosofia, da Antropologia, da Sociologia entre outras áreas que estudam o homem e suas relações no mundo. Mas, ainda é uma realidade dos cursos de licenciatura em EF dar maior ênfase e destaque aos conteúdos esportivos e biomédicos.

No que se refere ao DSC, superar tal relação implica dotar os professores com perspectivas de análise que os ajudem a compreender os contextos históricos, sociais, culturais e organizacionais nos quais envolvem o fenômeno da PS e a sua relação com as práticas corporais. Não mais se restringindo ao nível biológico, mas ampliando o entendimento e as possibilidades para o nível subjetivo e social.

\section{REFERÊNCIAS:}

Brandão CR. A educação popular e a educação de jovens e adultos: antes e agora. In: Machado MM, editor. Formação de educadores de jovens e adultos. Brasília: Secad/Mec; 2008. p.17-49.

Buss PM. Uma introdução ao conceito de promoção da saúde. In: Czeresnia D, Freitas CM. Promoção da saúde: conceitos, reflexões e tendências. 2a ed. Rio de Janeiro: Fiocruz; 2016. p.19-42.

Carvalho SR. As contradições da promoção à saúde em relação à produção de sujeitos e a mudança social. Ciênc Saúde Colet. 2004; 9 (3) :1849-1859.

Carvalho YM. Entre o biológico e o social. Tensões no debate teórico acerca da saúde na Educação Física. R. Motriviv. 2005; 17(24): 97-105.

Coelho C, Verdi M. Políticas e programas de atividade física: uma crítica à luz da promoção da saúde. Sau \& Transf Soc 2015; 6(3):96-108.

Conselho Nacional de Educação (BR). Parecer CEB no. 11/2000. Diretrizes Curriculares para a Educação de Jovens e Adultos. Brasília: Mec; 2000 [citado 21 out 2017]. Disponível em: http://portal.mec.gov.br/secad/arquivos/pdf/eja/legislacao/ parecer_11_2000.pdf.

Czeresnia D. O conceito de promoção da saúde e a diferença entre prevenção e promoção. In: Czeresnia D, Freitas CM. Promoção da saúde: conceitos, reflexões e tendências. $2^{a}$ ed. Rio de Janeiro: Fiocruz; 2016. p. 43-58.

Devide FP, Oliveira GA, Ferreira MS. Ampliando o campo de intervenção da educação física escolar a partir da análise da escada da aptidão para toda a vida. Pensar a Prática 2005; 8 (1): 1-19. 
Farinatti PTV, Ferreira MS. Saúde, Promoção da Saúde e Atividade Física: conceitos, princípios e aplicações. Rio de Janeiro: EdUERJ; 2006.

Ferreira MS. Agite antes de usar... A Promoção da Saúde em Programas Brasileiros de Promoção da Atividade Física: o caso do Agita São Paulo. Rio de Janeiro. Tese [Doutorado em Ciências] - Escola Nacional de Saúde Pública Sergio Arouca da Fiocruz; 2008.

Gil, ACG. Como elaborar projetos de pesquisa. 4a ed. São Paulo: Atlas; 2007.

Lefèvre $\mathrm{F}$, Lefèvre AMC. O Discurso do Sujeito Coletivo: um novo enfoque em pesquisa qualitativa (desdobramentos). Caxias do Sul: Educs; 2003.

Manzini EJ. Entrevista semi-estruturada: análise de objetivos e de roteiros. In: Anais do Seminário Internacional sobre Pesquisa e Estudos Qualitativos; 2004 mar 25-27; Bauru: USC; 2004.

Mezzaroba C. Ampliando o olhar sobre saúde na educação física escolar: críticas e possibilidades com o tema do meioambiente a partir da saúde coletiva. Motrivivência 2012; 38 (24): 231-246.
Ministério da Saúde (BR). Secretaria de Vigilância em Saúde. Política Nacional de Promoção da Saúde. Brasília: Ministério da Saúde; 2014 [citado 07 set 2017]. Disponível em: http:// bvsms.saude.gov.br/bvs/publicacoes/pnps_revisao_ portaria_687.pdf.

Nogueira JAD. A Educação Física e a Saúde. Rev Humanidades 2014; 60:102-113.

Pereira MG. Seleção dos participantes para o estudo. In: PEREIRA MG. Epidemiologia: Teoria e Prática. Rio de Janeiro: Guanabara Koogan; 2008. p. 338- 357.

Rodrigues de Sá GBA, Dornelles GC, Cruz KG, Amorin RCA, Andrade SSC, Oliveira TP, et al. O Programa Academia da Saúde como estratégia de promoção da saúde e modos de vida saudáveis: cenário nacional de implementação. Ciênc Saúde Colet. 2016; 21(6): 1849-1859.

Silva GC. O método científico na psicologia: abordagem qualitativa e quantitativa [internet]. 2010 nov 12; [citado 08 abr 2017]. Disponível em: http://www.psicologia.pt/artigos/textos/A0539.pdf.

Silva SE, Martins EC, Silva FM. A saúde na educação física: uma revisão sobre a prática escolar. Projeção e Docência, 2013; 4 (1): 29-35. 